\title{
Microtubule Dynamics and Neuronal Excitability: Advances on Cytoskeletal Components Implicated in Epileptic Phenomena
}

\author{
Giuditta Gambino $^{1} \cdot$ Valerio Rizzo $^{1} \cdot$ Giuseppe Giglia $^{1}\left[\right.$ G Giuseppe Ferraro $^{1} \cdot$ Pierangelo Sardo $^{1}$
}

Received: 19 May 2020 / Accepted: 5 September 2020 / Published online: 14 September 2020

(c) The Author(s) 2020

\begin{abstract}
Extensive researches have deepened knowledge on the role of synaptic components in epileptogenesis, but limited attention has been devoted to the potential implication of the cytoskeleton. The study of the development of epilepsy and hyperexcitability states involves molecular, synaptic, and structural alterations of neuronal bioelectric activity. In this paper we aim to explore the neurobiological targets involved in microtubule functioning and cytoskeletal transport, i.e. how dynamic scaffolding of microtubules can influence neuronal morphology and excitability, in order to suggest a potential role for microtubule dynamics in the processes turning a normal neuronal network in a hyperexcited one. Pathophysiological alterations of microtubule dynamics inducing neurodegeneration, network remodeling and relative impairment on synaptic transmission were overviewed. Recent researches were reported on the phosphorylation state of microtubule-associated proteins such as tau in neurodegenerative diseases and epileptic states, but also on the effect of microtubule-active agents influencing cytoskeleton destabilization in epilepsy models. The manipulation of microtubule polymerization was found effective in the modulation of hyperexcitability. In addition, it was considered the importance of microtubules and related neurotrophic factors during neural development since they are essential for the formation of a properly functional neuronal network. Otherwise, this can lead to cognitive deficits, hyperexcitability phenomena and neurodevelopmental disorders. Lastly, we evaluated the role of microtubule dynamics on neuronal efficiency considering their importance in the transport of mitochondria, cellular elements fulfilling energy requirements for neuronal activity, and a putative influence on cannabinoid-mediated neuroprotection. This review provides novel perspectives for the implication of microtubule dynamics in the development of epileptic phenomena.
\end{abstract}

Keywords Hyperexcitability $\cdot$ Microtubules $\cdot$ Epilepsy $\cdot$ Neurodevelopment $\cdot$ Cannabinoids $\cdot$ Neuroprotection

\section{Introduction: Epilepsy and Possible Neurobiological Targets}

Epilepsy is a common, chronic neurological disorder, characterized by recurring, unprovoked seizures that often requires long-term therapy with antiepileptic drugs (AEDs), unless it appears as drug-refractory (Schmidt and Löscher 2005; Tischfield et al. 2010). Epileptogenesis comprises the sequence of events leading to abnormal, hypersynchronous discharge of specific populations of cortical neurons (Bromfield et al. 2006). Epileptic seizures are characterized by

Giuseppe Giglia

giuseppe.giglia@unipa.it

1 Department of Experimental Biomedicine, Neuroscience and Advanced Diagnostics (Bi.N.D.), Sezione Di Fisiologia Umana G. Pagano, University of Palermo, Corso Tukory 129 , Palermo, Italy high-frequency bursts of action potentials hypersynchronously generated in a neuronal population, whose modification of bioelectric activity turns a normal neuronal network into a hyperexcitable one (Bromfield et al. 2006). Although studies on animal models and human tissue have suggested that the development of epilepsy and hyperexcitability states involve molecular, cellular and structural alterations (Rakhade and Jensen 2009), a clear understanding of mechanisms underlying structural changes in epilepsy has not been achieved yet. Among the experimentally induced epilepsies exploited for the investigation of underpinning mechanisms, temporal lobe epilepsy (TLE) originates from the alteration of normal discharge in the hippocampus (Téllez-Zenteno and Hernández-Ronquillo 2012); thus, this structure constitutes a brain area of particular interest in the field (Carletti et al. 2015; Gambino et al. 2018; Navas-Olive et al. 2020). Indeed, recent evidence report the paradoxical increase in 
structural re-organization and functional connectivity of limbic circuitry in patients with TLE (Bonilha et al. 2012).

Among the plethora of epilepsy-related neurobiological targets, research has been oriented mostly towards synaptic components, neurotransmitter mechanisms and/or metabolic pathways (Bialer et al. 2001; Scharfman 2007; Roseti et al. 2013; Maffei et al. 2015; Carletti et al. 2016a, 2018). The regulation of synaptic transmission is considered a key feature of numerous pathophysiological processes leading to seizures (Lepeta et al. 2016). Indeed, mutated synaptic proteins could be implied in pathways essential for presynaptic function, neurotransmission and general bioelectric homeostasis; thus, the so-called "synaptopathy" includes several inherited forms of epilepsy (Finelli et al. 2019). However, investigating on alternative molecular mechanisms is important to deepen knowledge on both etiology and pathophysiology of epilepsy, as well as to develop novel and more effective therapeutic strategies. Surprisingly enough, much work has been done on the role of synaptic components in the pathogenesis of epilepsy, but relatively little attention has been given to the potential role of the cytoskeleton. Only a few studies have investigated so far the putative role of the cytoskeleton on epilepsy. Indeed, deficiencies in cytoskeleton-related dynamics underpin several neurodevelopmental alterations and neurodegenerative disorders (Millecamps and Julien 2013). The neuronal cytoskeleton physiologically regulates core cellular processes including protein transport, cell division, and neurotrophic support, but also modulates voltage-gated ion channels activity and the affinity of several neurotransmitters for their receptors (Gardiner and Marc 2010). Here we aim to review novel mechanisms possibly implicated in epilepsy and hyperexcitability states involving alterations to the neuronal cytoskeleton, with particular attention to neurodevelopmental trajectories. In particular, we begin with an overview of how microtubule machinery is organized in neurons. Then, we carry out the description of microtubules dysfunction and its putative influence on neurodegeneration and hyperexcitability states, focusing on the importance of this eventual impairment during neurodevelopment. Overall, we present new intriguing mechanisms, which, if confirmed, could add insights to the topic and represent a target for new therapeutic strategies.

\section{Basics of Microtubule Organization in Central Nervous System}

The neuronal cytoskeleton constitutes a transport track comprising microtubules (MT), actin filaments (AF), intermediate filaments (IF), and associated proteins (AP) (Dent et al. 2010). It serves the intracellular mobilization of molecular cargos and organelles, modulating fundamental operations such as neuronal migration, neuritic growth and synaptic transmission (Conde and Cáceres 2009; Dent et al. 2010; Franker and Hoogenraad 2013; Sánchez-Huertas et al. 2016). Motor proteins driving neuronal transport direct intracellular cargos along either AF or MT (Dent et al. 2010; Franker and Hoogenraad 2013). MT, localized in the cell body and axonal and dendritic compartments, play an important part during neurogenesis and in mature neurons (Conde and Cáceres 2009; Compagnucci et al. 2016). MT serve for long-range transport into distal axons and dendrites, providing lines for kinesin and dynein motor proteins, respectively, to the microtubule plus-end or minus-end (Vale 2003; Hirokawa et al. 2009; Hoogenraad and Bradke 2009). Specifically, current live-cell evidence unveiled the presence of MT not only in the dendritic shaft but also in the spines, serving as specialized dendritic micro-domains fundamental as a wired switch for excitatory inputs (Sheng and Hoogen$\operatorname{raad} 2007$; Jaworski et al. 2009). MT dynamically structure the cells, thanks to the polymerization of $\alpha-\beta$-tubulin heterodimers that can be assembled in both parallel and anti-parallel configurations, thus determining MT intrinsic polarity (Sánchez-Huertas et al. 2016). In detail, MT position their plus ends away from the soma in axons, providing a unipolar organization that regulates anterograde and retrograde transport (Hirokawa et al. 2009; Hoogenraad and Bradke 2009). Whereas, in dendrites they arrange into bundles of mixed polarity in which plus ends are predominantly towards the soma, managing bidirectional cargo transport (Poulain and Sobel 2010). This finely regulated MT scaffolding underpins the typical morphology of specific neurons, their compartmentalization and paves the way for neuronal trafficking rules (Kapitein and Hoogenraad 2011; Rolls 2011).

Templates of tubulin ring complexes usually cap only the minus ends of MT; therefore, they tend to elongate only at their plus ends. This establishes the bases of the typical microtubule dynamic instability, ranging from the growing and shrinking of MT plus ends (Kapitein and Hoogenraad 2011). The precise MT orientation is essential for microtubule-based transport since the intrinsic polarity of MT is regulated by neuronal components driving transport either to the plus or minus ends (Kapitein and Hoogenraad 2011). Indeed, MT network is dependent on the strict control of microtubule dynamicity by numerous microtubule-associated proteins (MAP) that are responsible for MT assembly (depolymerization, polymerization, or fragmentation), transport, and stabilization (Poulain and Sobel 2010). In most non-neuronal cells, tubulin dimers and microtubule polymers require a rapid dynamic balance (Fanara et al. 2010). Whereas, in neurons, axonal and dendritic MT proved to be less dynamic in their rapid turnover due to the interaction with a specific subclass of microtubule-associated proteins that maintain the integrity of the microtubule-based axonal transport (Fanara et al. 1999, 2007). Stabilization of hyperdynamic MT is found to be related to neuroprotection in 
motor neuron degeneration (Fanara et al. 2007). Equally important to sustain neuronal health is tau, a MAP involved in axonal transport and microtubule stabilization. Tau oscillates between MT-bound and MT-unbound state for microtubules normal functioning, in a balance controlled by partially phosphorylated state of tau itself, by kinases and phosphatase enzymes (Morris et al. 2011; Lee and Leugers 2012).

All considered MT appear of core importance for the bioelectric features of neurons since they act as wires that biologically transmit and amplify electric signals via the flow of condensed ion clouds (Craddock et al. 2010). Thus, MT dynamics may have a specific function for neural development. Even if the role of microtubule dynamics on neuroexcitability and synaptic communication has been already suggested (Whatley and Harris 1996; Gardiner and Marc 2010), only recently investigations have pointed at elucidating whether this may directly contribute to epileptic phenomena (Carletti et al. 2016b). However, changes upon MT dynamics in the epileptic foci undoubtedly deserve further examination.

\section{Impairment of Microtubules in Neurodegeneration and Influence on Epilepsy}

The causal relationship between MT transport impairments and neural degeneration is still to uncover (Franker and Hoogenraad 2013; Millecamps and Julien 2013). It seems that damages to the intracellular transport can lead to vesicle-trafficking impairments, alterations of specific cargo interactions and defects in retrograde survival signals, with the ultimate result of neuronal death and loss of brain function (Saxena and Caroni 2007; Perlson et al. 2010). Indeed, impairments of neuronal transport pathways have been reconducted to axonal pathologies underlying Huntington's, Parkinson's and Alzheimer's diseases (Millecamps and Julien 2013), shedding new light on the dangerous linkages between aging and neuronal communication (Akhmedov et al. 2013). Identifying gene mutations upon molecules involved in neuronal transport pathways has brought about the idea that defective transport can directly trigger neurological diseases. For instance, detrimental mutations in $\alpha$ - or $\beta$-tubulin and microtubule-based motor proteins were uncovered and implicated in central and peripheral neurological diseases (Tischfield et al. 2010; Millecamps and Julien 2013; Yuen et al. 2019).

Recently, investigations have been conducted on epileptic disorders and eventual implications of the impairment of neuronal cytoskeleton were explored applying microtubule-active agents that targeted key mechanisms relating microtubule dysfunction and epileptogenesis (Fig. 1). In

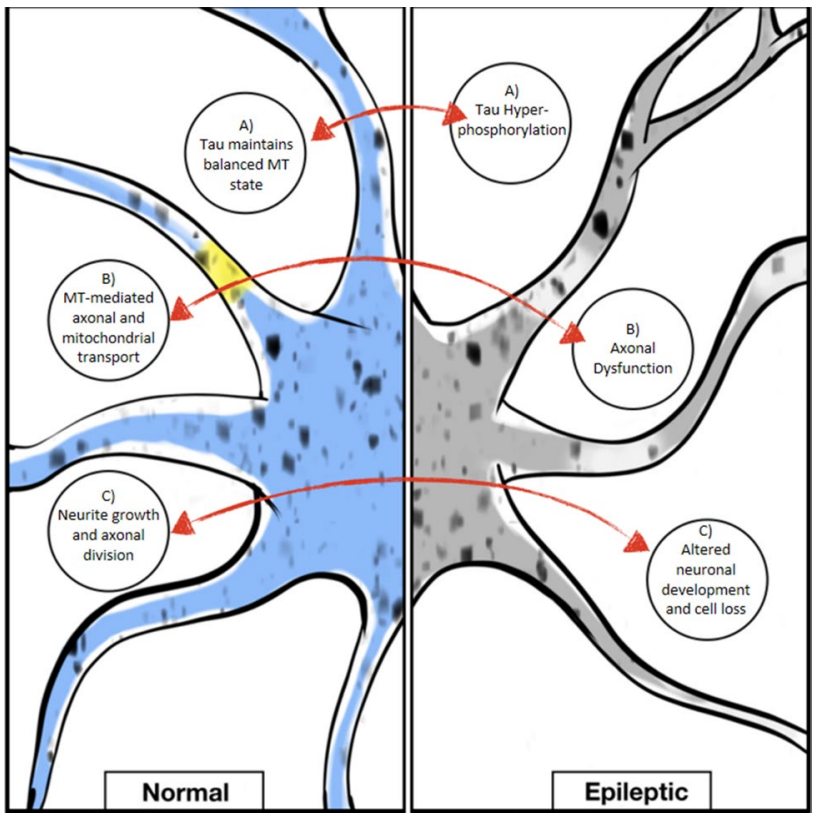

Fig. 1 Schematic representation of the main targets implicated in microtubule-mediated actions in normal versus epileptic neurons. (A) In epileptic neurons, it was found tau in hyper-phosphorylated state which is linked to aberrant network organization, whereas in normal neurons tau contributes to balanced microtubule (MT) state and proper functioning. (B) In epileptic neurons, axonal dysfunctions are found, whereas in normal neurons microtubule-mediated axonal and mitochondrial transport are maintained. (C) In epileptic states, microtubules are implicated in altered neuronal development, eventually leading to neuronal loss, whereas in normal neurons MT contribute to proper neurite growth and axonal division

a pathological environment, alterations to tau and the socalled "tauopathies" play a major role in neurodegeneration (Lee and Leugers 2012; Gunhild et al. 2015; Tai et al. 2020). Indeed, the neuronal balance in certain cases shifts to hyperphosphorylation of tau that does not bind anymore to MT, thus leading to cytoskeletal destabilization, axonal dysfunctions and ultimately, if cell viability is irreversibly blocked, to neuronal apoptosis (Lee and Leugers 2012; Kondo et al. 2015). Tau hyper-phosphorylation is a pathological feature observed in brain samples from epileptic patients (Sen et al. 2007; Puvenna et al. 2016; Liu et al. 2017) and its pharmacological manipulation provided anti-seizure effects in several chronic acquired models of epilepsy (Tian et al. 2010; Jones et al. 2012; Garg et al. 2018). For instance, Liu et al. (Liu et al. 2016) have recently proved that treatment with an inhibitor of tau phosphorylation protects from seizure induction and paroxysmal phenomena in acute and chronic models of epilepsy, as per other authors (Holth et al. 2013; Devos et al. 2013). The correlation of hyper-phosphorylated tau with epilepsy was also specifically located in the temporal lobe and associated with cognitive decline in patients behaviorally assessed before temporal lobe resection (Tai et al. 
2016). Molecularly, tau hyper-phosphorylation is considered to trigger aberrant network re-organization such as mossy fibers sprouting, putatively mediated by NR2B subunit of NMDA glutamate receptors, which is deemed as a fundamental marker for epilepsy development (Tian et al. 2010; Decker et al. 2016). Furthermore, the network hyperexcitability associated with tau modification can implicate, among the proposed mechanisms, the enhancement of presynaptic glutamate release (Vossel et al. 2016, 2017). In line with this, seizure-induced neuronal loss and axonal damage may lead to the development of aberrant connections between limbic structures and eventually result in the reorganization of the limbic network (Spencer 2002). Lastly, tau deletion has been associated with reduced severity of tumor-related epilepsy, together with a functional dysregulation of glutamate homeostasis (Hatcher et al. 2020).

Microtubule cytoskeleton seems strongly implicated in seizure-dependent network remodeling since the expression of $\alpha$-tubulin rises, together with several MAPs and hyper-phosphorylated tau, within the sprouting of mossy fibers (Pollard et al. 1994; Gardiner and Marc 2010; Tang et al. 2014). In detail, hippocampal kindling in the rat was associated with aberrant synaptic reconstruction, due to the increase in the dentate gyrus of MAP-2, a structural protein determining the amount of MT in dendrites (Tang et al. 2014). As well, augmentation of $\alpha 1$-tubulin mRNA levels was found in the kindled hippocampus of rodents, together with sprouting and reorganization of neural networks (Sato and Abe 2001). In addition, the up-regulation of genes associated with tubulin has been found in the human brain from patients with drug-resistant focal epilepsy (Xi et al. 2011; Machado et al. 2019). A relevant study outlined that several kinesin-knockout mice are characterized by epileptic phenotype evidenced by electroencephalogram abnormalities. The authors explained this considering the impairment of GABA A receptor-mediated synaptic transmission (Nakajima et al. 2012). Other studies showed that augmented gene expression of $\alpha$-tubulin and an altered microtubule formation in kainic acid model of epilepsy contributed to aberrant neurogenesis in the hippocampus (Represa et al. 1993; Hendriksen et al. 2001). Nonetheless, the exact implication of aberrant tubulin has not been clarified yet, since a down-regulation of both $\alpha$ - and $\beta$-tubulin proteins was found in mesial TLE (Yang et al. 2006), due to the alteration of tubulin acetylation by the deacetylase Sirtuin 2. Among the few studies on the epileptic brain, it was also observed the unbalance of actin cytoskeleton assembly and disassembly following status epilepticus. In acute and chronic chemical models of epilepsy the acute depolymerization and long-term remodeling of F-actin were found, thus potentially contributing to the process of epileptogenesis (Zeng et al. 2007; Zhang et al. 2014). Recently, the use of dexamethasone, known to control actin polymerization, reduced the damage to actin filaments in pilocarpine-induced temporal lobe epilepsy (Yang et al. 2019). It is worth noting that infantile epileptic syndromes characterized by spasm (West syndrome) have been empirically treated with steroids since the ' $60 \mathrm{~s}$. (Chutorian et al. 1968). More recently, steroids have been used to treat status epilepticus in slow-wave sleep (ESES) (Moosa 2019). However, treatment with steroids is not effective in other forms of epilepsy (Mehta et al. 2015). This suggests that they only act on a specific etiologic mechanism rather than on epilepsy per se. On this point, it has been reported a mutation on PHACTR1, a molecule critical for the regulation of protein phosphatase 1 and the actin cytoskeleton, in patients with West syndrome (Hamada et al. 2018).

In the light of these data, it seems that pharmacological manipulation of cytoskeletal and microtubule functioning could be intriguingly relevant to the development and the control of epilepsy, as summarized in Table 1. Previous study provided information that davunetide, preserving microtubule dynamics, can reduce kainate toxicity (Zemlyak et al. 2009). To this purpose, previous data explored the genesis and maintenance of epileptic activity when perturbing the microtubule assembly process in the hippocampus, in both intact neuronal network and isolated brain slices in vivo and in vitro in the rat (Carletti et al. 2016b). The main novelty of the study was represented by the choice of pharmacological molecules widely administered in cancer therapy as antimitotic such as nocodazole and paclitaxel (Jordan and Wilson 2004). This paper showed for the first time that nocodazole protects and modulates electrophysiological paroxysmal activity in rat TLE models, by reducing the onset and duration of epileptic discharge in vivo and also of hippocampal bursting activity in vitro (Carletti et al. 2016b). On the other hand, it was also described a case of non-convulsive status epilepticus induced by chemotherapeutic application of paclitaxel and discovered by electroencephalographic examination of an oncologic patient (Illán-Gala et al. 2015). The pharmacokinetic interaction of AEDs with chemotherapeutic drugs has been already outlined and ascribed to the susceptibility of cytochromes (CYP) enzymes to drug inducers or inhibitor, but complex effects of microtubule agents on seizures could hint a more specific interaction (Bénit and Vecht 2016). Other studies investigated MT-active agents in neurodegenerative diseases. For instance, it was found a protective role for paclitaxel in Alzheimer's diseases. Indeed, this MTstabilizing agent, as well as other taxanes with comparable potency in promoting tubulin assembly, protects against amyloid- $\beta(\mathrm{A} \beta)$ toxicity and enhances neuronal survival, at low doses (Michaelis et al. 2005). Also in Huntington's neurodegeneration, paclitaxel treatment acted on an early step of MT destabilization remarkably boosting survival of primary striatal neurons expressing a toxic mutant protein 
Table 1 Microtubule-active agents in epileptic states

\begin{tabular}{|c|c|c|c|c|}
\hline Research papers & $\begin{array}{l}\text { Stud- } \\
\text { ies on } \\
\text { humans }\end{array}$ & Studies on animal models & $\begin{array}{l}\text { Microtubule-active agents } \\
\text { applied }\end{array}$ & Main effects obtained \\
\hline Jones et al. (2012) & $\mathrm{X}$ & Pentylenetetrazole rat model & Sodium Selenate & $\begin{array}{l}\text { Tau Dephosphorilation, neuropro- } \\
\text { tection }\end{array}$ \\
\hline Liu et al. (2016) & $\mathrm{X}$ & Pentylenetetrazole rat model & Sodium Selenate & $\begin{array}{l}\text { Tau Dephosphorilation, neuropro- } \\
\text { tection }\end{array}$ \\
\hline Devos et al. (2013) & $\mathrm{X}$ & Pentylenetetrazole mouse model & Central oligodeoxynucleotides & $\begin{array}{l}\text { Reduction of Tau levels, neuropro- } \\
\text { tection }\end{array}$ \\
\hline Holth et al. (2013) & $X$ & In vitro mice epilepsy model & Tau genotyping & $\begin{array}{l}\text { Reduction of Tau levels, neuropro- } \\
\text { tection }\end{array}$ \\
\hline Yang et al. (2006) & Yes & $\mathrm{X}$ & $\mathrm{X}$ & $\begin{array}{l}\text { Down-regulation of tubulins asso- } \\
\text { ciated with epilepsy }\end{array}$ \\
\hline Zeng et al. (2007) & $X$ & Kainate mouse model & Calcineurin inhibitor & $\begin{array}{l}\text { Stabilization of actin dynamics } \\
\text { reduces seizures }\end{array}$ \\
\hline Yang et al. (2019) & $\mathrm{X}$ & Pilocarpine mouse model & Dexamethasone & $\begin{array}{l}\text { Control of actin polymerization } \\
\text { reduces seizures }\end{array}$ \\
\hline Zemlyak et al. (2009) & $\mathrm{X}$ & Kainate mouse model & Davunetide & $\begin{array}{l}\text { Protection of microtubule func- } \\
\text { tioning and reduction of kainate } \\
\text { neurotoxicity }\end{array}$ \\
\hline Carletti et al. (2016b) & $\mathrm{X}$ & $\begin{array}{l}\text { In vivo and in vitro rat epilepsy } \\
\text { models }\end{array}$ & Nocodazole, Paclitaxel & $\begin{array}{l}\text { Modulation of microtubule polym- } \\
\text { erization and neuroprotection } \\
\text { exerted by nocodazole }\end{array}$ \\
\hline Illán-Gala et al. (2015) & Yes & $X$ & Paclitaxel & $\begin{array}{l}\text { Induction of non-convulsive status } \\
\text { epilepticus }\end{array}$ \\
\hline
\end{tabular}

(Trushina et al. 2003). It could be counterintuitive that cytotoxic drugs support neuronal survival as in (Michaelis et al. 2005; Carletti et al. 2016b), in fact these drugs can interfere with processes initiated by excessive stabilization of the cytoskeleton and loss of dynamic instability. Furthermore, blocking early MT depolymerizing signals associated with several insults, could be a way to trigger cascades that enhance cell survival, acting as a supervising system for cell destiny. This innovative viewpoint on epileptogenesis has been supported by a growing number of authors focusing on the reduced axonal and dendritic transport of cargos such as mitochondria that physiologically regulate neuronal excitability (Vossel et al. 2010, 2017; Morris et al. 2011).

\section{Neurodevelopmental Aspects of Microtubule Dysfunction and Epileptogenesis}

The overviewed importance of microtubule-dependent functioning in neuronal hyperexcitability could sink deeper roots early in the neurodevelopment of synapses (as summarized in Table 2). The modulation of key synaptic factors during neurodevelopment can be considered as a protective strategy against epileptogenesis (Aronica et al. 2011; Grabenstatter et al. 2014). Microtubule machinery plays a

Table 2 Role of microtubule dysfunction on neurodevelopment

\begin{tabular}{lll}
\hline Research papers & Target studied & Main effects evidenced \\
\hline $\begin{array}{l}\text { Franker and Hoogenraad (2013), Huang et al. (2012), Liu and } \\
\text { Dwyer (2014) }\end{array}$ & MAP & Axon formation and navigation \\
$\begin{array}{l}\text { Augustyniak et al. (2017) } \\
\text { Poulain and Sobel (2007) }\end{array}$ & MAP 2 & Mitochondrial biogenesis \\
de Nijs et al. (2006) & Stathmin 2 & Neuritogenesis, axonogenesis and dendritogenesis \\
Xia et al. (2003), Nakajima et al. (2012) & EFHC1 & Altered cell division and juvenile myoclonic epilepsy \\
& KIF5A & Alteration on GABA A functioning and predisposi- \\
& & tion to seizures \\
\hline
\end{tabular}


prominent role in neurodevelopment and is finely regulated by mechanisms like phosphorylation, acetylation, tyrosination, and glutathionylation (Compagnucci et al. 2016). MT helps the developing brain in the navigation and formation of axons (Franker and Hoogenraad 2013; Mutch et al. 2016). Even during the process of mitosis, MT migrate from the centrosome and modulate cell division by attachment to chromosomes. In this context, MAPs are particularly useful for neuronal migration, helping the nucleokinesis, in axonal navigation (Huang et al. 2012; Liu and Dwyer 2014) and mitochondrial biogenesis (Augustyniak et al. 2017). Indeed, the implication of MAP 2 on the efficiency of mitochondria in neuronal differentiation has been examined for the impact on neurodegenerative disorders (Augustyniak et al. 2017). Additionally, neuritogenesis, axonogenesis, and dendritogenesis are essential processes relying on the specific dynamics of the microtubule cytoskeleton, for instance microtubules polarized ends are differently arranged from immature neuritis to mature dendrites (Poulain and Sobel 2010). Some specific tubulin binding proteins, for instance belonging to stathmin family, were found to regulate axonal branching without affecting growth cone size (Poulain and Sobel 2007). All considered, microtubule transport not only supports the restructuring of membranes, organelles and macromolecules but also contributes to the elaboration of dendritic trees (Sharp et al. 1997).

These orchestrated events, when impaired, lead to malformations of a functional neuronal network, usually evidenced by cognitive deficits and neurodevelopmental disorders such as microencephaly, lissencephaly, polymicrogyria, and infantile epileptic syndromes (Cushion et al. 2014; Compagnucci et al. 2016). Among the numerous proteins that were implicated in these processes, mutations of EFHC1 protein have been related to juvenile myoclonic epilepsy (de Nijs et al. 2006). This protein accumulating at the centrosome during interphase, is fundamental for cell division. Also kinesin proteins undergo neurodevelopmental modifications leading to hyperexcitability such as the postnatal loss of kinesin gene KIF5A predisposing to seizures (Xia et al. 2003). When KIF5A is deficient in neurons, EEG recordings evidenced epileptic seizures probably due to impaired GABA A trafficking (Nakajima et al. 2012). Importantly related to neurodevelopmental alterations of microtubules is a brain-derived neurotrophic factor (BDNF), trafficked one way and back along microtubules between the cell periphery and the nucleus (Butowt and von Bartheld 2007). Some authors assert that BDNF favors neuronal survival and growth in epileptic rats (Yu et al. 2019), whereas others agree that excessive expression of BDNF is involved in the pathogenesis of hippocampal hyperexcitability and epilepsy (Gardiner and Marc 2010). Overall, the genetic implication of neurotrophic factors and neurodevelopmental impairments could represent a target for studies on long-lasting modifications of synaptic plasticity and the related morphological changes of synapses. This could bring awareness on the importance of monitoring and preventing microtubules dysfunction eventually triggering pathophysiological alterations of neuronal activity.

\section{Novel Effects of Microtubules on Neuronal Excitability: Role of Mitochondria and Cannabinoids}

A deeper insight on minute effects of microtubules functioning within neuronal machinery can be gained considering the most recent advances on the field, i.e. the role of mitochondrial transport in microtubule-mediated control of neuronal activity. The proper, unceasing mitochondria trafficking within the neuron is indeed essential to fulfill energy requirements of neurons for instance to efficiently perform neurosignalling or to re-establish ion gradients (Ogawa et al. 2016). Trafficking of neuronal mitochondria in both axons and dendrites is functional to the proper activity such as basic energy supply, but also to their degradation when damaged or aged. In this processes, many MT motors and adaptor proteins support the distribution to precise cellular compartments, the flux and movement of neuronal mitochondria (Melko and Abdu 2018). In particular, several microtubule cytoskeleton-associated proteins are involved in the axonal mitochondrial transport such as TRAK1 and DISC1, whose dysfunction has been studied for putative impact on neuronal impairment and possibly on pathologies of the CNS (Manji et al. 2012). It seems that mitochondria are transported in the anterograde direction by kinesins (Pereira et al. 1997), while dynein might be their retrograde motor (Habermann et al. 2001). However, the exact way microtubule motors are concertedly regulated to guarantee mitochondrial transport is still a matter of debate. It has been suggested that axonal transport of mitochondria is fundamental to maintain a uniform distribution of them throughout the neuron, to the ultimate purpose of proper neuronal efficiency. Specifically, functional mitochondria with high potential are transported out into the axon, while the old or damaged ones with low potential are transported back to the cell body (Miller and Sheetz 2004). For instance, an eventual impairment in MTmediated transport could be targeted as a precursor of a progressive accumulation of damaged mitochondria, which is typical of neurological conditions like Alzheimer's disease (AD, Ye et al. 2015).

Considering that neuronal cells are extremely sensitive to even mild changes in mitochondrial dynamics, intriguing researches have recently investigated the role of cannabinoid receptors on mitochondrial activity in the brain (Hebert-Chatelain et al. 2014). Indeed, the cannabinoid system represents a widely known endogenous repertoire 
that is implicated in a plethora of pathophysiological functions, such as learning and memory, neuronal excitability and neuroadaptation (Marsicano et al. 2003; Ligresti et al. 2016). Within the context of neuronal excitability, researches support the neuroprotection exerted by cannabinoids on bioelectric balance in neurons (Carletti et al. 2017; Gambino et al. 2020). This protection could be also exerted on the maintenance of cytoskeletal dynamics, considering that activation of cannabinoid receptors type $1(\mathrm{CBr} 1)$ has been associated with cytoskeletal reorganization to the purpose of stabilizing axonal morphology (Tortoriello et al. 2014).

The discovery of specific localization of $\mathrm{CBr} 1$ within CA1 hippocampal mitochondrial membranes sets out a novel path in the experimental field of neuroexcitability (HebertChatelain et al. 2014; Busquets-Garcia et al. 2015). Indeed, Hebert-Chatelain et al. (Hebert-Chatelain et al. 2016) demonstrated that mitochondrial $\mathrm{CBr} 1$ triggers a cascade of events decreasing brain mitochondrial activity, necessary for the acute effects of cannabinoids on mitochondrial mobility, synaptic depression and eventually memory impairments. For instance, in hyperexcited states, cultured hippocampal neurons treated with cannabinoid agonist showed higher $\mathrm{Ca}^{2+}$ uptake by mitochondria (Ryan et al. 2009). Cannabinoid-mediated mitochondrial processes could also be influenced by a Ca-dependent endogenous mediator, nitric oxide (NO; Tedesco et al. 2010; Lipina et al. 2014).

The suggested alteration of intracellular activity is of striking importance when considering eventual long-term impact on the pathogenesis of neurological disorders. Considering all this, it could be conceivable an influence of $\mathrm{CBr} 1$, on the transport and activity of mitochondrial influencing excitability of the cells, putatively involving elements associated with neuronal transport such as microtubules. Targeted studies will be needed to explore this fascinating hypothesis here formulated to explore the contribution of cannabinoids and microtubule motors on mitochondrial activity to investigate the influence on neuronal excitability.

\section{Conclusive Remarks}

The present review provides a snapshot on cytoskeletal components implicated in the pathogenesis of neurological disorders and, above all, of epileptic conditions. Increasing attention has been dedicated to the microtubule cytoskeleton in the last years for its compelling coordination of complex elements of neuronal transport, ultimately regulating synaptic activity.

Here we propose a neurobiological perspective of the possible targets orchestrated by microtubules functioning with minute molecular details comprising, among the others, mitochondrial transport and cannabinoid-mediated effects. The neurodevelopmental etiology of microtubule dysfunction was examined to explore the early stages of neuronal impairment and to individuate eventual chances of therapeutic intervention. Nonetheless, the ultimate goal was to evaluate the translational application of manipulating microtubule dynamics in the alteration of neuronal excitability and the related, not-well pharmacologically controlled pathologies such as epilepsy.

Author Contributions GG, VR, GG and GF selected the papers to review and wrote the manuscript. PS coordinated the project and wrote the manuscript.

Funding Open access funding provided by Università degli Studi di Palermo within the CRUI-CARE Agreement.

\section{Compliance with Ethical Standards}

Conflict of interest All authors declare that they have no conflict of interest.

Ethical Approval This is a review of literature with no animal or human study that could require an ethical approval.

Informed Consent This is a review with no experiments performed on humans. All authors of the review agree with the content.

Open Access This article is licensed under a Creative Commons Attribution 4.0 International License, which permits use, sharing, adaptation, distribution and reproduction in any medium or format, as long as you give appropriate credit to the original author(s) and the source, provide a link to the Creative Commons licence, and indicate if changes were made. The images or other third party material in this article are included in the article's Creative Commons licence, unless indicated otherwise in a credit line to the material. If material is not included in the article's Creative Commons licence and your intended use is not permitted by statutory regulation or exceeds the permitted use, you will need to obtain permission directly from the copyright holder. To view a copy of this licence, visit http://creativecommons.org/licenses/by/4.0/.

\section{References}

Akhmedov K, Rizzo V, Kadakkuzha BM et al (2013) Decreased response to acetylcholine during aging of aplysia neuron R15. PLoS ONE 8(12):e84793. https://doi.org/10.1371/journ al.pone.0084793

Aronica E, Iyer A, Zurolo E, Gorter JA (2011) Ontogenetic modifications of neuronal excitability during brain maturation: developmental changes of neurotransmitter receptors. Epilepsia 52:3-5. https://doi.org/10.1111/j.1528-1167.2011.03222.x

Augustyniak J, Lenart J, Zychowicz M, Stepien PP, Buzanska L (2017) Mitochondrial biogenesis and neural differentiation of human iPSC is modulated by idebenone in a developmental stagedependent manner. Biogerontology 18:665-677. https://doi org/10.1007/s10522-017-9718-4

Bénit CP, Vecht CJ (2016) Seizures and cancer: drug interactions of anticonvulsants with chemotherapeutic agents, tyrosine kinase inhibitors and glucocorticoids. Neuro-Oncol Pract 3:245-260. https://doi.org/10.1093/nop/npv038 
Bialer M, Johannessen S, Kupferberg H et al (2001) Progress report on new antiepileptic drugs: a summary of the Fifth Eilat Conference (EILAT V). Epilepsy Res 43:11-58. https://doi.org/10.1016/ S0920-1211(00)00171-6

Bonilha L, Nesland T, Martz GU et al (2012) Medial temporal lobe epilepsy is associated with neuronal fibre loss and paradoxical increase in structural connectivity of limbic structures. Neurodegeneration. https://doi.org/10.1136/jnnp-2012-302476

Bromfield EB, Cavazos JE, Sirven JI (eds) (2006) An Introduction to epilepsy basic mechanisms underlying seizures and epilepsy. Chapter 1, Basic mechanisms underlying seizures and epilepsy. AES, Chicago, pp 1-44

Busquets-Garcia A, Desprez T, Metna-Laurent M et al (2015) Dissecting the cannabinergic control of behavior: the where matters. BioEssays 37:1215-1225. https://doi.org/10.1002/bies.20150 0046

Butowt R, von Bartheld C (2007) Conventional kinesin-i motors participate in the anterograde axonal transport of neurotrophins in the visual system. J Neurosci Res 3253:3244-3253. https://doi. org/10.1002/jnr

Carletti F, Gambino G, Rizzo V et al (2015) Cannabinoid and nitric oxide signaling interplay in the modulation of hippocampal hyperexcitability: study on electrophysiological and behavioral models of temporal lobe epilepsy in the rat. Neuroscience 303:149-159. https://doi.org/10.1016/j.neuroscien ce.2015.06.047

Carletti F, Gambino G, Rizzo V et al (2016a) Involvement of TRPV1 channels in the activity of the cannabinoid WIN 55,212-2 in an acute rat model of temporal lobe epilepsy. Epilepsy Res 122:5665. https://doi.org/10.1016/j.eplepsyres.2016.02.005

Carletti F, Sardo P, Gambino G et al (2016b) Hippocampal hyperexcitability is modulated by microtubule-active agent: evidence from in vivo and in vitro epilepsy models in the rat. Front Cell Neurosci 10:1-14. https://doi.org/10.3389/fncel.2016.00029

Carletti F, Gambino G, Rizzo V et al (2017) Neuronal nitric oxide synthase is involved in CB/TRPV1 signalling: focus on control of hippocampal hyperexcitability. Epilepsy Res 138:18-25. https ://doi.org/10.1016/j.eplepsyres.2017.09.018

Carletti F, Rizzo V, Gambino G et al (2018) Comparative study of the effects exerted by $\mathrm{N}$-valproyl-L-phenylalanine and $\mathrm{N}$-valproylL-tryptophan on CA1 hippocampal epileptiform activity in rat. Curr Pharm Des 24:1849-1858. https://doi.org/10.2174/13816 12824666180409095530

Chutorian AM, Gold AP, Low NL (1968) Steroid therapy of noninfantile (childhood) myoclonic epilepsy. Neurology 18:304-305

Compagnucci C, Piermarini E, Sferra A et al (2016) Cytoskeletal dynamics during in vitro neurogenesis of induced pluripotent stem cells (iPSCs). Mol Cell Neurosci 77:113-124. https://doi. org/10.1016/J.MCN.2016.10.002

Conde C, Cáceres A (2009) Microtubule assembly, organization and dynamics in axons and dendrites. Nat Rev Neurosci 10:319-332. https://doi.org/10.1038/nrn2631

Craddock TJA, Tuszynski JA, Priel A, Freedman H (2010) Microtubule ionic conduction and its implications for higher cognitive functions. J Integr Neurosci 9:103-122. https://doi.org/10.1142/ S0219635210002421

Cushion TD, Paciorkowski AR, Pilz DT et al (2014) De novo mutations in the beta-tubulin gene TUBB2A cause simplified gyral patterning and infantile-onset epilepsy. Am J Hum Genet 94:634-641. https://doi.org/10.1016/j.ajhg.2014.03.009

de Nijs L, Lakaye B, Coumans B et al (2006) EFHC1, a protein mutated in juvenile myoclonic epilepsy, associates with the mitotic spindle through its N-terminus. Exp Cell Res 312:2872-2879. https ://doi.org/10.1016/j.yexcr.2006.05.011

Decker JM, Krüger L, Sydow A et al (2016) The Tau/A152T mutation, a risk factor for frontotemporal-spectrum disorders, leads to
NR2B receptor-mediated excitotoxicity. EMBO Rep 17:552-569. https://doi.org/10.15252/embr.201541439

Dent EW, Merriam EB, Hu X (2010) The dynamic cytoskeleton: backbone of dendritic spine plasticity. Curr Opin Neurobiol. https:// doi.org/10.1016/j.conb.2010.08.013

Devos SL, Goncharoff DK, Chen G et al (2013) Antisense reduction of Tau in adult mice protects against seizures. J Neurosci 33:1288712897. https://doi.org/10.1523/JNEUROSCI.2107-13.2013

Fanara P, Oback B, Ashman K et al (1999) Identification of MINUS, a small polypeptide that functions as a microtubule nucleation suppressor. EMBO J 18:565-577. https://doi.org/10.1093/emboj $/ 18.3 .565$

Fanara P, Banerjee J, Hueck RV et al (2007) Stabilization of hyperdynamic microtubules is neuroprotective in amyotrophic lateral sclerosis. J Biol Chem 282:23465-23472. https://doi. org/10.1074/jbc.M703434200

Fanara P, Husted KH, Selle K et al (2010) Changes in microtubule turnover accompany synaptic plasticity and memory formation in response to contextual fear conditioning in mice. Neuroscience 168:167-178. https://doi.org/10.1016/j.neuroscien ce.2010.03.031

Finelli MJ, Aprile D, Castroflorio E et al (2019) The epilepsy-associated protein TBC1D24 is required for normal development, survival and vesicle trafficking in mammalian neurons. Hum Mol Genet 28:584-597. https://doi.org/10.1093/hmg/ddy370

Franker MAM, Hoogenraad CC (2013) Microtubule-based transport-basic mechanisms, traffic rules and role in neurological pathogenesis. J Cell Sci 126:2319-2329. https://doi.org/10.1242/ jcs. 115030

Gambino G, Rizzo V, Giglia G et al (2020) Cannabinoids, TRPV and nitric oxide: the three ring circus of neuronal excitability. Brain Struct Funct 225(1):1-15. https://doi.org/10.1007/s00429-01901992-9

Gambino G, Allegra M, Sardo P et al (2018) Brain distribution and modulation of neuronal excitability by indicaxanthin from opuntia ficus indica administered at nutritionally-relevant amounts. Front Aging Neurosci 10:133. https://doi.org/10.3389/fnagi .2018 .00133

Gardiner J, Marc J (2010) Disruption of normal cytoskeletal dynamics may play a key role in the pathogenesis of epilepsy. Neurosci 16:28-39. https://doi.org/10.1177/1073858409334422

Garg N, Joshi R, Medhi B (2018) Cracking novel shared targets between epilepsy and Alzheimer's disease: need of the hour. Rev Neurosci 29:425-442. https://doi.org/10.1515/revne uro-2017-0064

Grabenstatter HL, Cogswell M, Cruz Y et al (2014) Effect of spontaneous seizures on GABA A receptor a 4 subunit expression in an animal model of temporal lobe epilepsy. Epilepsia. https://doi. org/10.1111/epi.12771

Gunhild NR, Jørgen W, Nielsen E et al (2015) Cerebrospinal fluid biomarkers in familial forms of Alzheimer's disease and frontotemporal dementia. Dement Geriatr Cogn Disord 40:54-62. https ://doi.org/10.1159/000381828

Habermann A, Schroer TA, Griffiths G, Burkhardt JK (2001) Immunolocalization of cytoplasmic dynein and dynactin subunits incultured macrophages: enrichment on early endocytic organelles. J Cell Sci 114:229-240

Hamada N, Ogaya S, Nakashima M et al (2018) De novo PHACTR1 mutations in West syndrome and their pathophysiological effects. Brain 141(11):3098-3114. https://doi.org/10.1093/brain/awy246

Hatcher A, Yu K, Meyer J, Aiba I, Deneen B, Noebels JL (2020) Pathogenesis of peritumoral hyperexcitability in an immunocompetent CRISPR-based glioblastoma model. J Clin Invest 130(5):22862300. https://doi.org/10.1172/JCI133316 
Hebert-Chatelain E, Desprez T, Serrat R et al (2016) A cannabinoid link between mitochondria and memory. Nature 539:555-559. https://doi.org/10.1038/nature20127

Hebert-Chatelain E, Reguero L, Puente N et al (2014) Cannabinoid control of brain bioenergetics: exploring the subcellular localization of the CB 1 receptor. Mol Metab 3:495-504. https://doi. org/10.1016/j.molmet.2014.03.007

Hendriksen H, Datson NA, Ghijsen WEJM et al (2001) Altered hippocampal gene expression prior to the onset of spontaneous seizures in the rat post-status epilepticus model. Eur J Neurosci 14:1475-1484. https://doi.org/10.1046/j.0953-816x.2001.01778 . $\mathrm{x}$

Hirokawa N, Noda Y, Tanaka Y, Niwa S (2009) Kinesin superfamily motor proteins and intracellular transport. Nat Rev Mol Cell Biol 10:682-696. https://doi.org/10.1038/nrm2774

Holth JK, Bomben VC, Reed JG et al (2013) Tau loss attenuates neuronal network hyperexcitability in mouse and Drosophila genetic models of epilepsy. J Neurosci. https://doi.org/10.1523/JNEUR OSCI.3191-12.2013

Hoogenraad CC, Bradke F (2009) Control of neuronal polarity and plasticity-a renaissance for microtubules? Trends Cell Biol 19:669-676. https://doi.org/10.1016/J.TCB.2009.08.006

Huang J, Roberts AJ, Leschziner AE, Reck-Peterson SL (2012) Lis1 acts as a "clutch" between the ATPase and microtubule-binding domains of the dynein motor. Cell 150:975-986. https://doi. org/10.1016/j.cell.2012.07.022

Illán-Gala I, Díaz de Terán FJ, Alonso P, Aguilar-Amat M-J (2015) Nonconvulsive status epilepticus secondary to paclitaxel administration. Epilepsy Behav Case Rep 4:20-22. https://doi. org/10.1016/j.ebcr.2014.12.001

Jaworski J, Kapitein LC, Gouveia SM et al (2009) Dynamic microtubules regulate dendritic spine morphology and synaptic plasticity. Neuron. https://doi.org/10.1016/j.neuron.2008.11.013

Jones NC, Nguyen T, Corcoran NM et al (2012) Targeting hyperphosphorylated tau with sodium selenate suppresses seizures in rodent models. Neurobiol Dis. https://doi.org/10.1016/j. nbd.2011.12.005

Jordan MA, Wilson L (2004) Microtubules as a target for anticancer drugs. Nat Rev Cancer 4:253-265. https://doi.org/10.1038/nrc13 17

Kapitein LC, Hoogenraad CC (2011) Which way to go? Cytoskeletal organization and polarized transport in neurons. Mol Cell Neurosci 46:9-20. https://doi.org/10.1016/J.MCN.2010.08.015

Kondo A, Shahpasand K, Mannix R et al (2015) Antibody against early driver of neurodegeneration cis P-tau blocks brain injury and tauopathy. Nature 523:431-436. https://doi.org/10.1038/ nature 14658

Lee G, Leugers CJ (2012) Tau and Tauopathies. Prog Mol Biol Transl Sci 107:263-293. https://doi.org/10.1016/B978-0-12-38588 3-2.00004-7

Lepeta K, Lourenco MV, Schweitzer BC et al (2016) Synaptopathies: synaptic dysfunction in neurological disorders-a review from students to students. J Neurochem 138:785-805

Ligresti A, De Petrocellis L, Di MV (2016) Pleiotropic physiological and pathological roles through complex pharmacology. Physiol Rev 96:1593-1659. https://doi.org/10.1152/physrev.00002 .2016.-Apart

Lipina C, Irving AJ, Hundal HS (2014) Mitochondria: a possible nexus for the regulation of energy homeostasis by the endocannabinoid system? Am J Physiol Endocrinol Metab 307:1-13. https://doi. org/10.1152/ajpendo.00100.2014.-The

Liu G, Dwyer T (2014) Microtubule dynamics in axon guidance. Neurosci Bull 30:569-583. https://doi.org/10.1007/s1226 4-014-1444-6
Liu S, Shen Y, Shultz SR et al (2017) Accelerated kindling epileptogenesis in $\mathrm{Tg} 4510$ tau transgenic mice, but not in tau knockout mice. Epilepsia 58:136-141. https://doi.org/10.1111/epi.13847

Liu SJ, Zheng P, Wright DK et al (2016) Sodium selenate retards epileptogenesis in acquired epilepsy models reversing changes in protein phosphatase $2 \mathrm{~A}$ and hyperphosphorylated tau. Brain 139:1919-1938. https://doi.org/10.1093/brain/aww116

Machado RA, Benjumea-Cuartas V, Zapata Berruecos JF et al (2019) Reelin, tau phosphorylation and psychiatric complications in patients with hippocampal sclerosis and structural abnormalities in temporal lobe epilepsy. Epilepsy Behav 96:192-199

Maffei A, Trebak M, Khanna R et al (2015) Stim and Orai proteins in neuronal $\mathrm{Ca} 2+$ signaling and excitability. Front Cell Neurosci. https://doi.org/10.3389/fncel.2015.00153

Manji H, Kato T, Di Prospero NA et al (2012) Impaired mitochondrial function in psychiatric disorders. Nat Rev Neurosci 13:293-307

Marsicano G, Goodenough S, Monory K (2003) CB1 cannabinoid receptors and on-demand defense against excitotoxicity. Science (80- ). https://doi.org/10.1126/science.1088208

Mehta V, Ferrie CD, Cross JH, Vadlamani G (2015) Corticosteroids including ACTH for childhood epilepsy other than epileptic spasms. Cochrane Database Syst Rev. https://doi. org/10.1002/14651858.CD005222.pub3

Melkov A, Abdu U (2018) Regulation of long-distance transport of mitochondria along microtubules. Cell Mol Life Sci 75:163-176. https://doi.org/10.1007/s00018-017-2590-1

Michaelis ML, Ansar S, Chen Y et al (2005) $\beta$-Amyloid-induced neurodegeneration and protection by structurally diverse microtubulestabilizing agents. J Pharmacol Exp Ther 312:659-668. https:// doi.org/10.1124/jpet.104.074450

Millecamps S, Julien J-P (2013) Axonal transport deficits and neurodegenerative diseases. Nat Rev Neurosci 14:161-176. https://doi. org/10.1038/nrn3380

Miller KE, Sheetz MP (2004) Axonal mitochondrial transport and potential are correlated. J Cell Sci 117:2791-2804. https://doi. org/10.1242/jcs.01130

Moosa ANV (2019) Antiepileptic drug treatment of epilepsy in children. Continuum 25:381-407

Morris M, Maeda S, Vossel K, Mucke L (2011) The many faces of Tau. Neuron 70:410-426. https://doi.org/10.1016/J.NEURO N.2011.04.009

Mutch CA, Poduri A, Sahin M et al (2016) Disorders of microtubule function in neurons: imaging correlates. Am J Neuroradiol 37:528-535. https://doi.org/10.3174/ajnr.A4552

Nakajima K, Yin X, Takei Y et al (2012) Molecular motor KIF5A is essential for GABAA receptor transport, and KIF5A deletion causes epilepsy. Neuron 76:945-961. https://doi.org/10.1016/j. neuron.2012.10.012

Navas-Olive A, Valero M, Jurado-Parras T et al (2020) Multimodal determinants of phase-locked dynamics across deep-superficial hippocampal sublayers during theta oscillations. Nat Commun 11(1):2217. https://doi.org/10.1038/s41467-020-15840-6

Ogawa F, Murphy LC, EL Malavasi V et al (2016) NDE1 and GSK3 $\beta$ associate with TRAK1 and regulate axonal mitochondrial motility: identification of cyclic AMP as a novel modulator of axonal mitochondrial trafficking. ACS Chem Neurosci 7:553-564. https ://doi.org/10.1021/acschemneuro.5b00255

Pereira AJ, Dalby B, Stewart RJ et al (1997) Mitochondrial association of a plus end-directed microtubule motor expressed during mitosis in Drosophila. J Cell Biol 136(5):1081-1090. https://doi. org/10.1083/jcb.136.5.1081

Perlson E, Maday S, Fu M et al (2010) Retrograde axonal transport: pathways to cell death? Trends Neurosci 33(7):335-344. https:// doi.org/10.1016/j.tins.2010.03.006 
Pollard H, Khrestchatisky M, Moreau J et al (1994) Correlation between reactive sprouting and microtubule protein expression in epileptic hippocampus. Neuroscience 61:773-787. https://doi. org/10.1016/0306-4522(94)90401-4

Poulain FE, Sobel A (2007) The "SCG10-LIke Protein" SCLIP is a novel regulator of axonal branching in hippocampal neurons, unlike SCG10. Mol Cell Neurosci 34:137-146

Poulain FE, Sobel A (2010) The microtubule network and neuronal morphogenesis: dynamic and coordinated orchestration through multiple players. Mol Cell Neurosci 43:15-32. https://doi. org/10.1016/J.MCN.2009.07.012

Puvenna V, Engeler M, Banjara M et al (2016) Is phosphorylated tau unique to chronic traumatic encephalopathy? Phosphorylated tau in epileptic brain and chronic traumatic encephalopathy. Brain Res. https://doi.org/10.1016/j.brainres.2015.11.007

Rakhade SN, Jensen FE (2009) Epileptogenesis in the immature brain: emerging mechanisms. Nat Rev Neurol 5(7):380-391. https://doi.org/10.1038/nrneurol.2009.80

Represa A, Pollard H, Moreau J et al (1993) Mossy fiber sprouting in epileptic rats is associated with a transient increased expression of $\alpha$-tubulin. Neurosci Lett 156:149-152. https:// doi.org/10.1016/0304-3940(93)90460-3

Rolls MM (2011) Neuronal polarity in Drosophila: sorting out axons and dendrites. Dev Neurobiol 1:419-429. https://doi. org/10.1002/dneu.20836

Roseti C, Fucile S, Lauro C et al (2013) Fractalkine/CX3CL1 modulates GABAA currents in human temporal lobe epilepsy. Epilepsia 54:1834-1844. https://doi.org/10.1111/epi.12354

Ryan D, Drysdale AJ, Lafourcade C et al (2009) Cannabidiol targets mitochondria to regulate intracellular ca2+ levels. J Neurosci 29:2053-2063. https://doi.org/10.1523/JNEUR OSCI.4212-08.2009

Sánchez-Huertas C, Freixo F, Viais R et al (2016) Non-centrosomal nucleation mediated by augmin organizes microtubules in postmitotic neurons and controls axonal microtubule polarity. Nat Commun 7:12187. https://doi.org/10.1038/ncomms 12187

Sato K, Abe K (2001) Increases in mRNA levels for Ta1- tubulin in the rat kindling model of epilepsy. Brain Res 904:157-160. https://doi.org/10.1016/S0006-8993(01)02459-3

Saxena S, Caroni P (2007) Mechanisms of axon degeneration: from development to disease. Prog Neurobiol 83(3):174-191. https ://doi.org/10.1016/j.pneurobio.2007.07.007

Scharfman HE (2007) The neurobiology of epilepsy. Curr Neurol Neurosci Rep 7:348-354. https://doi.org/10.1007/s1191 0-007-0053-Z

Schmidt D, Löscher W (2005) Drug resistance in epilepsy: putative neurobiologic and clinical mechanisms. Epilepsia 46(6):858877. https://doi.org/10.1111/j.1528-1167.2005.54904.x

Sen A, Thom M, Martinian L et al (2007) Pathological tau tangles localize to focal cortical dysplasia in older patients. Epilepsia 48:1447-1454. https://doi.org/10.111 1/j.1528-1167.2007.01107.x

Sharp DJ, Yu W, Ferhat L et al (1997) Identification of a microtubule-associated motor protein essential for dendritic differentiation. J Cell Biol 138(4):833-843. https://doi.org/10.1083/ jcb.138.4.833

Sheng M, Hoogenraad CC (2007) The postsynaptic architecture of excitatory synapses: a more quantitative view. Annu Rev Biochem. https://doi.org/10.1146/annurev.biochem.76.06080 5.160029

Spencer SS (2002) Neural networks in human epilepsy: evidence of and implications for treatment. Epilepsia 43:219-227. https:// doi.org/10.1046/j.1528-1157.2002.26901.x

Tai XY, Liu JYW, Reeves C et al (2016) Hyperphosphorylated tau in patients with refractory epilepsy correlates with cognitive decline: a study of temporal lobe resections. Brain 139:24412455. https://doi.org/10.1093/brain/aww 187

Tai C, Chang CW, Yu GQ et al (2020) Tau reduction prevents key features of autism in mouse models. Neuron 106(3):421-437. e11. https://doi.org/10.1016/j.neuron.2020.01.038

Tang L, Lu Y, Zheng W, Li Y (2014) Overexpression of MAP-2 via formation of microtubules plays an important role in the sprouting of mossy fibers in epileptic rats. J Mol Neurosci 53:103-108. https://doi.org/10.1007/s12031-013-0204-4

Tedesco L, Valerio A, Dossena M et al (2010) Cannabinoid receptor stimulation impairs mitochondrial biogenesis in mouse white adipose tissue, muscle, and liver the role of eNOS, p38 MAPK, and AMPK pathways. Diabetes 59:2826-2836. https ://doi.org/10.2337/db09-1881

Téllez-Zenteno JF, Hernández-Ronquillo L (2012) A review of the epidemiology of temporal lobe epilepsy. Epilepsy Res Treat 2012:1-5. https://doi.org/10.1155/2012/630853

Tian F-F, Zeng C, Ma Y-F et al (2010) Potential roles of Cdk5/p35 and tau protein in hippocampal mossy fiber sprouting in the PTZ kindling model. Clin Lab 56:127-136

Tischfield MA, Baris HN, Wu C et al (2010) Human TUBB3 mutations perturb microtubule dynamics, kinesin interactions, and axon guidance. Cell. https://doi.org/10.1016/j.cell.2009.12.011

Tortoriello G, Morris CV, Alpar A et al (2014) Miswiring the brain: $\Delta 9$-tetrahydrocannabinol disrupts cortical development by inducing an SCG10/stathmin-2 degradation pathway. EMBO J 33:668-685. https://doi.org/10.1002/embj.201386035

Trushina E, Heldebrant MP, Perez-Terzic CM et al (2003) Microtubule destabilization and nuclear entry are sequential steps leading to toxicity in Huntington's disease. Proc Natl Acad Sci USA 100(21):12171-12176. https://doi.org/10.1073/ pnas. 2034961100

Vale RD (2003) The molecular motor toolbox for intracellular transport. Cell 112:467-480. https://doi.org/10.1016/S0092 -8674(03)00111-9

Vossel KA, Ranasinghe KG, Beagle AJ et al (2016) Incidence and impact of subclinical epileptiform activity in Alzheimer's disease. Ann Neurol 80:858-870. https://doi.org/10.1002/ ana. 24794

Vossel KA, Tartaglia MC, Nygaard HB et al (2017) Epileptic activity in Alzheimer's disease: causes and clinical relevance. Lancet Neurol 16:311-322

Vossel KA, Zhang K, Brodbeck J et al (2010) Tau reduction prevents $A \beta$-induced defects in axonal transport. Science 330(6001):198. https://doi.org/10.1126/science.1194653

Whatley VJ, Harris RA (1996) The cytoskeleton and neurotransmitter receptors. Int Rev Neurobiol 39:113-143. https://doi. org/10.1016/s0074-7742(08)60665-0

Xi ZQ, Wang XF, Shu XF et al (2011) Is intractable epilepsy a tauopathy? Med Hypotheses 76:897-900. https://doi.org/10.1016/j. mehy.2011.03.003

Xia C-H, Roberts EA, Her L-S et al (2003) Abnormal neurofilament transport caused by targeted disruption of neuronal kinesin heavy chain KIF5A. J Cell Biol 161:55-66. https://doi. org/10.1083/jcb.200301026

Yang JW, Czech T, Felizardo M et al (2006) Aberrant expression of cytoskeleton proteins in hippocampus from patients with mesial temporal lobe epilepsy. Amino Acids 30:477-493. https ://doi.org/10.1007/s00726-005-0281-y

Yang N, Li YC, Xiong TQ et al (2019) Dexamethasone ameliorates the damage of hippocampal filamentous actin cytoskeleton but is not sufficient to cease epileptogenesis in pilocarpine induced epileptic mice. Epilepsy Res 154:26-33. https://doi. org/10.1016/j.eplepsyres.2019.04.009 
Ye X, Sun X, Starovoytov V, Cai Q (2015) Parkin-mediated mitophagy in mutant hAPP neurons and Alzheimer's disease patient brains. Hum Mol Genet 24:2938-2951

Yu X, Guan Q, Wang Y et al (2019) Anticonvulsant and anti-apoptosis effects of salvianolic acid B on pentylenetetrazole-kindled rats via AKT/CREB/BDNF signaling. Epilepsy Res 154:9096. https://doi.org/10.1016/j.eplepsyres.2019.05.007

Yuen YTK, Guella I, Roland E et al (2019) Case reports: novel TUBG1 mutations with milder neurodevelopmental presentations. BMC Med Genet 20(1):95. https://doi.org/10.1186/ s12881-019-0827-6

Zemlyak I, Manley N, Vulih-Shultzman I et al (2009) The microtubule interacting drug candidate NAP protects against kainic acid toxicity in a rat model of epilepsy. J Neurochem 111:12521263. https://doi.org/10.1111/j.1471-4159.2009.06415.x
Zeng LH, Xu L, Rensing NR et al (2007) Kainate seizures cause acute dendritic injury and actin depolymerization in vivo. $\mathrm{J}$ Neurosci 27:11604-11613. https://doi.org/10.1523/JNEUR OSCI.0983-07.2007

Zhang YF, Xiong TQ, Tan BH et al (2014) Pilocarpine-induced epilepsy is associated with actin cytoskeleton reorganization in the mossy fiber-CA3 synapses. Epilepsy Res 108:379-389. https://doi.org/10.1016/j.eplepsyres.2014.01.016

Publisher's Note Springer Nature remains neutral with regard to jurisdictional claims in published maps and institutional affiliations. 